\title{
The effectiveness of the problem-posing method based on android applications in mathematics learning
}

\author{
Intan Indiati, Universitas PGRI Semarang, iin.indi3@gmail.com, ORCID: 0000-0003-3124-609X \\ *Supandi Supandi, Universitas PGRI Semarang, supandi@upgris.ac.id, ORCID: 0000-0002-3235-2970 \\ Lilik Ariyanto, Universitas PGRI Semarang, lilikariyanto@upgris.ac.id, ORCID: 0000-0002-2336-1605 \\ Widya Kusumaningsih, Universitas PGRI Semarang, widya.kusuma81.wk@gmail.com,0RCID: 0000-0001- \\ 8003-8217 \\ *Corresponding Author
}

\begin{abstract}
This study aims to see the learning outcomes of prospective mathematics teacher students on problem-posing abilities using the Android Package Kit (APK). It is necessary to have innovation in learning so that it has a better problem-posing ability. During a pandemic like this time teaching and learning activities experience many obstacles. To overcome these obstacles, it is necessary to do learning innovations, one of which is online learning. This study used a quasi-experimental design using the first experimental group and the second experimental group known as the pretest-posttest control group design. The subjects of this study were second-semester students majoring in Mathematics Education. Collecting data using the online method or online (Covid-19 pandemic). The sample was determined using a purposive sampling technique to determine the first experimental class as many as 28 students and the second experimental class as many as 29 students. The experimental class uses problem-based learning, while the second experimental class uses direct learning according to the material content. The material in this research is opportunity theory. The results of the observed data were analyzed quantitatively. The learning results show that learning using APK was effective in improving learning outcomes (both in problem-based learning classes and indirect learning). In the evaluation phase, improvements were made to the APK that had been developed after reflection on the results in the field at the implementation stage. The results showed that online learning based on android applications as a very helpful means of maximizing teaching and learning activities.
\end{abstract}

Keywords: Problem-posing, Online learning, APK

$\begin{array}{lll}\text { Received: } 02.11 .2020 & \text { Accepted: } 14.12 .2020 & \text { Published: 23.01.2021 }\end{array}$

\section{INTRODUCTION}

Solving problem is a top priority in school mathematics. Central to the valuable role played by problemsolving is the quality of the problem posed (Leavy, 2019). So that solving the problem must be based on a goal. A business or activity that is carried out deliberately, regularly and with plans is nothing but an educational goal. The role of this effort is to develop or change behaviour according to what is desired. Education can also be interpreted as a process of cultivating developing values, knowledge and skills. Thus, the function that must be carried out by education is to provide a conducive facility. Educational objectives can be achieved through schools as formal institutions as places for students to carry out learning activities. Educational goals can also be achieved if the teacher can become a qualified facilitator. So that teachers should be aware of the importance of math challenges and should feel confident when working with challenging math assignments with their students (Leikin, 2019). But in reality, there are still many teachers who have difficulty achieving learning goals. The success of teachers in proposing problem was found to be still low. Also, they have the highest difficulty in understanding the problem posed (Işık, 2011). Prospective teachers have difficulty posing problem for certain patterns and solving the problem posed (Kar, 2010). The problem list (with or without solutions) also takes into account originality, diversity, and correctness of problem and solution statements (Voice, 2020). The number of issues raised is also important. Then a detailed description of all ideas and behaviours.

To pose a problem is generally to raise a problem in a free situation. According to (Lee, 2020) posing a problem with the answer given refers to the appropriate problem to be answered. Submitting problem that contains certain information comes from problem tables, graphs, and so on. Asking a question for a problem situation is called posing a question from the problem situation provided. Asking a problem which corresponds to a given calculation is a problem of a given mathematical calculation as well. With the help 
of the problem-posing guide module to guide students to do problem-posing (Hwang, 2020). So that the teacher guides students to be able to solve a problem. However, there are still many students who have difficulty solving a problem in everyday life. Students have difficulty adjusting the difficulty level of the problem (Şengül, 2012). If the teacher provides problem-posing activities to students during class learning, students become active in class and allow them to think analytically (Cildir, 2011). It is believed that problem posing is a learning model where the more experienced, the better it will be for student learning. Therefore, the class that has higher mathematical thinking will have a higher problem posing as well $\mathrm{Xu}$, 2020). Given the confirmed role of influence in shaping student problem-posing performance, school administrators are advised to increase teachers' awareness and understanding of the importance of affective characteristics in problem posing. Furthermore helping them improve students' mathematical problem posing abilities with the affective intervention (Guo, 2020). All the teachers showed an increased understanding of the problem posed after the workshop (Cai, 2019). Thus they identified the need to provide practice and preparation for mathematics teachers with appropriate support, both for an appreciation of problem posing and for the development of problem-posing skills as a necessity for classroom activities (Koichu, 2019).

Mathematical understanding is a spectrum and students have different proficiency ranges about a concept (Calabrese, 2020). This is done to connect the problem is the problem with the problem faced in everyday life. So that the correlation of knowledge with the problem of everyday life must be encouraged. If the teacher only uses sample questions in the book, students will not be interested in. So, the atmosphere will be uncomfortable. This atmosphere will hinder student motivation. Talking about students' learning motivation, the higher the class the motivation towards academic attention is diverted and divided among many components, such as family, heterogeneous relationships, entertainment and this hinders their academic achievement (Gupta, 2016). Apart from the division of time, a common problem among teenagers is depression. In a study, Damayanti (2017) suggested program intervention to reduce depression in adolescents is to provide health educators through special mental health in schools. Mental health specialities in school include counselling, stress management programs, time management, and screening about negative life events. So that problem-posing activities not only contribute to improving problemsolving skills but also help students become more aware of their learning, improve their ability to monitor and assess the learning process, and as a result, develop metacognitive awareness (Akben, 2020). According to Chen (2020) students in problem posing learning gradually became actively involved in thinking and participating in a lively classroom atmosphere. Other than that, posing a problem stimulates students 'thinking and enhances students' understanding of mathematical concepts and clarification of mathematical principles. A high level of intelligence can make it easier for individuals to think rationally and the results can be maximized (Hardanti, 2016). So that there is a significant relationship between the intelligence structure and student achievement is a significant relationship between job behaviour and student academic achievement (Ulya, 2018). However, all of that is still controlled personally. Because personal control significantly predicts student performance. That is, students' beliefs about their capacity to control for the causative factors will be good predictors of their performance. Moreover, in a classroom environment, By involving PP, students generate as many problems as teachers or textbooks do. They are encouraged to raise a problem that may be meaningful to them personally or socially (Çakır, 2020). By applying effective learning methods to improve learning outcomes in various media and using handheld learning media, it can increase students' willingness to continue to be involved in learning (Sung, 2013). Moreover, students' beliefs about the factors causing their academic success and failure contributed significantly to academic achievement (Rosito, 2020). This has a good effect on the current situation because students are required to study at home without direct teacher supervision. However, if students have confidence and pleasure in themselves, it can improve students' learning abilities. students generate as many problems as teachers or textbooks do.

Learning situations by utilizing technology have great potential because it can lead students to various representations and develop a deeper understanding of certain mathematical concepts (Zhang, 2020). The use of media with technology in the learning process is proven to help the learning process by conveying information through various formats. However, a problem can arise if the correct media is used. The problem found is divided into five categories: speed, clarity, quality, media diversity, and suitability (Lange, 2020). Given the many social media tools, schools need to choose which social media to use in the classroom. So that students feel happy and comfortable in online learning. In the study Vie (2018) students admitted to feeling happy with online learning as it is today but occasionally getting annoyed when the connection was bad. This cannot be underestimated, it must also be realized that ineffective media delivery can cause a problem in learning. Other than that, able to influence learning outcomes. In a study, Barisone (2019) suggested that the use of web applications for learning technical-practical skills also improves students' conceptual learning. 
Many technologies can be used, one of which is in the form of applications. Applications that were created to communicate can now be useful for education (Dharma, 2017). Research Amasha (2020) revealed that mobile applications are more effective than traditional methods to improve student outcomes in mathematics. This shows that the effectiveness of current applications in developing students 'cognitive skills and improving students' mathematical abilities. It was also found in experimental research Kularbphettong (2015) that the group had significantly better learning achievement and benefited from using different courses. So that students can improve their abilities. Meanwhile, the benefit of the teacher is to support the teacher in handling and managing the course of learning. Husni (2013) developed an application for children with autism where there are learning materials for children to manipulate menu in Early Mathematics Ability (EMA) using companion studies. This approach aims to help blind children increase their interest and enthusiasm for learning and increase their understanding of the material to be delivered. For now, many experts have developed applications for the visually impaired. So, they don't find it difficult to use online learning applications like this. Sari (2019)developed an interactive learning media application with a gamification approach to smartphones. So that by developing applications in education can help students in learning.

\section{METHODS}

This study used a quasi-experimental design using the first experimental group and the second experimental group known as the pretest-posttest control group design. A quasi-experimental design was used in this study because each subject was not grouped randomly, but subjects were grouped from the start in one class when students entered and were registered as students or in the opportunity theory course. The following is the research design in this study (Table 1)

Table 1. Research Design

\begin{tabular}{|l|l|l|l|}
\hline \multicolumn{1}{|c|}{ Group } & \multicolumn{3}{|c|}{ Treatment } \\
\hline First Experiment & 0 & $\mathrm{X} 1$ & 0 \\
\hline $\begin{array}{l}\text { Second } \\
\text { Experiment }\end{array}$ & 0 & $\mathrm{X} 2$ & 0 \\
\hline
\end{tabular}

with:

$\begin{array}{ll}\text { The first experiment } & \text { : a group that was given PBM } \\ \text { Second experiment } & \begin{array}{l}\text { :a group was given DL } \\ \text { : Pretest and posttest of } \\ \text { problem-posing skills, }\end{array} \\ \text { O } & \text { mathematical critical thinking. } \\ & \text { : PBM } \\ \text { X1 } & \text { : DL }\end{array}$

In this study, students' initial mathematical abilities were divided into high, medium, and low groups. This study examines the impact that appears on the subject as a result of the applied learning treatment, namely the problem-posing ability, critical thinking and mathematical resilience of students. The independent variables in this study are problem-based learning (PBM) and direct learning (DL). The dependent variable in this study is the ability to pose problems, think critically.

\section{RESULTS}

\section{Achievement of Mathematical Problem Submission Ability}

The data analysis of mathematical PPA achievement is obtained from the posttest results which include average, standard deviation and category EMA and PBM and DL approach. Recapitulation of PPA achievement data mathematically was found that the average mathematical PPA achievement of students with moderate and overall EMA categories who get DL is higher than students who get PBM. Furthermore, the average mathematical PPA value of students with high EMA who get PBM is higher than students who get DL. To clarify the picture of the average achievement Mathematical PPA of students who get PBM and students who get DL are shown in Figure 1. 


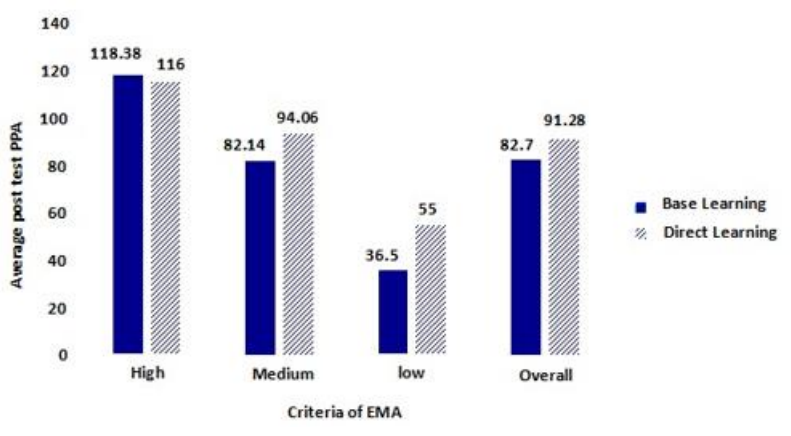

Figure 1. Average Student Mathematical PPA

The achievement of PPA who get PBM has sig> 0,05 which means that $\mathrm{H}_{0}$ is accepted, in other words, that the mathematical PPA data of students who get PBM are normally distributed. Furthermore, for PPA achievement data using $\mathrm{DL}$, the value is sig $>0,05$ which means that $\mathrm{H}_{0}$ is accepted, in other words, that the mathematical PPA data of students who get DL are normally distributed. It is shown that $\mathrm{H}_{0}$ is accepted because sig $>0,05$, this means that the data on the achievement of mathematical PPA of students who get PBM and DL have homogeneous variances. Furthermore, testing the difference in the average achievement of students' mathematical PPA at PBM and DL using the t-test. The statistical test used was the t-test with a significance level of $\alpha=0.05$. Based on the results of the Independent Sample Test, the Sig. (2-tailed) = 0.311 . Because the value of $0.311>0.05$, it can be concluded that the average PPA achievement in the two research classes is not significantly different.

The results of the data normality test of students' mathematical PPA achievement in learning Opportunity Theory based on learning and EMA will be described in detail in this section. The results of the normality test for the achievement of students' mathematical PPA for high, medium, low and overall EMA in both studies have this value is sig $>0,05$, which means that $\mathrm{H}_{0}$ is accepted, in other words, that the student mathematical PPA sample for EMA is high, medium, low and overall is normally distributed. Furthermore, for students' mathematical PPA data for high, medium, low and overall EMA categories, first the variance homogeneity test was carried out with the Levene test.

Recapitulation of the results from the homogeneity test of the variance of achievement of mathematical for high, medium, low and overall EMA categories based on learning with $\alpha=0.05$. It is shown that $\mathrm{H}_{0}$ for EMA is high, medium, low and overall accepted, this means that the data on students' mathematical PPA achievement for high, medium, low and overall EMA in PBM and DL have a homogeneous variance.

Furthermore, testing the difference in the mean data of students' mathematical PPA attainment for high, medium, low and overall EMA in PBM and DL using the t-test. The hypothesis formulation for testing the difference in the mean difference of students' mathematical CAR for high, medium, low, and overall EMA categories is as follows. The recapitulation of the t-test results indicated that there was no difference in the average achievement of students' mathematical PPA for PBM and DL for the high, medium, low and overall categories.

\section{Improved Mathematical Problem Proposal (PPA) Ability}

Descriptive Analysis of Student Mathematical PPA Improvement Data PBM and DL normalized gain for high KAM is included in the medium category. Meanwhile, the normalized gain of PBM and DL for KAM is medium, low and overall is in a low category. To clarify the description of the average increase in the mathematical KPM of students who get PBM and DL as follows:

The data analysis of mathematical PPA improvement was obtained from the results of the pretest and posttest which included mean, standard deviation and based on the category of EMA and PBM and DL. The recapitulation of mathematical PPA improvement data is shown that the average value of the increase in mathematical PPA of students with high, medium and overall EMA categories who get PBM (PBM) is higher than students who get DL (DL). Meanwhile, the average value of the increase in the mathematical PPA of students with low category EMA who get DL is higher than students who get PBM. PBM and DL normalized gain for high EMA are included in the medium category. Meanwhile, the normalized gain of PBM and DL for EMA is medium, low and overall is in a low category.

\section{Inferential Analysis of Student Mathematical PPA Improvement Data}

Inferential analysis of student mathematical PPA improvement data based on learning and EMA (Figure 2). The tests applied to the student's mathematical PPA improvement data were normality, homogeneity and 
mean difference tests.

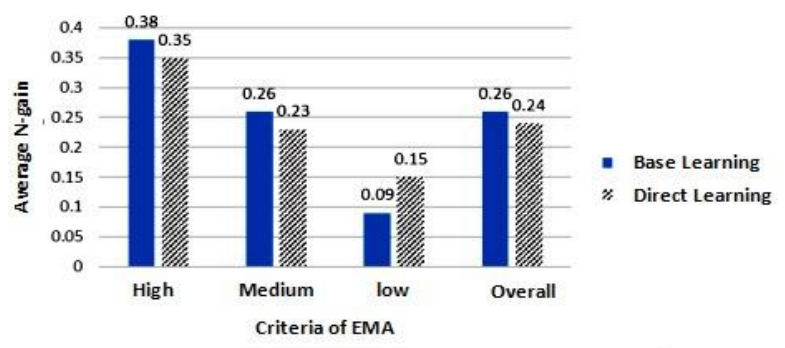

Figure 2. The Average Improvement Of Students' Mathematical PPA based on Learning and EMA

The average increase in the PPA of students in the DL class is not normally distributed and the data distribution graph tends to be Moderate Positive Skewness, therefore the average N-gain data is transformed using the square root transformation so that it is obtained in the Shapiro-Wilk column. With statistic $=0.935$, with $\mathrm{df}=29$, and Sig. 0.075 . Then, the two classes have homogeneous variances with the Sig. 0.271>0.05. Thus, the results of the N-Gain PPA mean transformation of students can be continued with the two-way ANOVA test.

\section{DISCUSSION}

It is very important for prospective teachers, who should assess the problem posed by their students and guide them about these. To find out the appropriate problem-posing skills of prospective teachers to choose, translate, understand and edit the model and the possible difficulties they may encounter during this process. A four-item test of fractions that fits the problem-posing model was used for data collection. Each suitability of the problem statement with the problem-posing model is analyzed. In the study IPEK (2011) the results were shown prospectively. The success of teachers in posing problem was found below. They have the highest difficulty "understanding" the problem posed. The higher the grade level, the higher the student's problem-posing ability. Overall, teachers predicted more complex problem requiring a specification of functional relationships than was evidenced in student responses, even students at higher grade levels. students are much more likely to pose a less complex problem that involves tallying or counting numbers. Also, the level of suitability of individual predictions for each teacher, especially for problem-posing skills, is relatively low.

To explore how teachers can develop their understanding of the thinking of students involved in problem-posing so that teachers can use problem posing to teach mathematics. Theoretically, the problemposing approach can be an effective tool for many students because it is easily accessed by students in various mathematical achievements. Problem posing occurs more frequently during lectures. This will help students understand the importance of problem-building skills, in the language of thinking skills. The inability to construct a student's problem helps the lecturer to easily diagnose one of the following complications: students lack relevant conceptual knowledge, students lack knowledge processing skills, students lack sufficient, students cannot draw correct relationships between ideas.

Teachers have difficulty raising the problem for certain patterns and solving the problem posed. In the ability of problem posing, prospective teachers still have difficulty raising problem for certain patterns and solving the problem posed. Prospective teachers have difficulty asking questions and they tend to prefer to work on questions rather than ask questions. Prospective teachers have difficulty asking questions because they don't know what things and how to do them to ask questions, they prefer to work on calculation questions. This is consistent with what Crespo (2008) stated that many prospective teachers have difficulty raising problem. prospective teachers must be able to connect the problem faced in everyday life. Some teachers do not pose the type of problem students pos, they pose a limited number of the problem providing only one problem type for an assignment. During the lesson, the sample questions in the book are used. Considering the problem of routine textbooks that do not attract students' attention becomes uncomfortable with their capacity, students do not encounter similar incidents in real life, and the importance of the problem raised by the teacher is evident. Proposing and solving a problem through student experience is an important element in learning. Thus, the use and perpetuation of the knowledge learned are contributed. Prospective teachers should be compared according to their problem-posing skills status. Especially in learning branch, the correlation of knowledge with the problem of everyday life should 
be encouraged. Students should be encouraged to connect the problem with a problem faced in their daily life and this should not be ignored.

Students have difficulty adjusting the difficulty level of the problem, unable to have complete subject knowledge and match the elementary school level during the problem-posing process. And it was determined that some students stated that they did not experience difficulties and did not make recommendations for solutions. Students can display free questions posing skills but they cannot solve the problem according to the problem-solving steps (Şengül, 2012). This situation occurs because students have never studied problem posing and solving before. It was determined that the students had difficulty matching the primary school level and in adjusting the difficulty level of the problem and they believed that they could overcome these difficulties by gaining experience in time.

Regarding the challenges faced by prospective teachers, it can be overcome by doing problem posing and solving exercises, checking different sources besides textbooks, and dealing with various types of questions (Şengül, 2012). For now, based on existing research, prospective teachers still have the low problem-posing ability. This happens because the teachers have been accustomed to learning in situations without a position since the study. So that the result is that it is not easy for teachers, especially to apply to pose in their class. For this reason, problem-posing is one of the challenges in the learning process of mathematics in the classroom, both for students and teachers themselves. Problem posing is a problem formulated by a student in line with the influence of problem-solving. a problem that is formed through problem posing can develop in difficulty levels over time. However, it depends on the role of a teacher to be a good influence. As time goes by, there needs to be a renewal of learning methods. It needs things that can be done to improve learning.

In education, it is necessary to provide innovation so that the education system is getting better. Various kinds of obstacles faced in education. One of them is a child with autistic disorder, which needs special handling to handle cases like this. In this case, there is research that provides guidance using application assistance. This application was created to facilitate students' understanding of learning. the design process is based on the analysis of user needs by paying attention to functional and non-functional aspects. Functional aspects relate to the features that have been given, while non-functional aspects relate to user needs, ease of operation, and application appearance. Users are also satisfied with the application and sixty per cent of the recommended applications can be used as a learning tool for children with autism. The results are proven to be effective in learning because they can help students increase their enthusiasm for learning so that it helps improve student understanding. Learning today is mostly still using books which are relatively more difficult to understand and tend to be boring for students. One of the popular learning media developments is Android-based learning media. learning via mobile devices reduces the formality of the learning experience and helps engage resisting learners and increases their self-confidence (Grice, 2019). Learning using a mobile application provides positive results on student achievement. Following the post-test and pre-test data as well as the questionnaire given to students, it was found that an increase in test results and student attitudes towards learning mathematics. The increase in student test scores was considered high, while the development of students' attitudes towards learning was still in the moderate category. This is because cell phone technology has become a necessity for students every day, as well as the use of this technology has not received a high response in learning mathematics (Supandi, 2018).

Improvement in the world of education must and continues to be carried out, especially reforming the curriculum in line with the flow of modern technology. Mobile applications are more effective than traditional methods of enhancing student learning in mathematics in its current state (Mohamed, 2020). This proves that this learning media application can increase children's knowledge and understanding. Students claim to be happier and more satisfied with a learning application that has been made (Afhara, 2013). To make a learning application in the design process it must be based on an analysis of user needs with attention to functional and non-functional aspects. The functional aspect relates to the features that have been provided, while non-functional is related to user requirements, ease of operation, and application appearance. According to Kularbphettong (2015) class, groups that use applications in learning have significantly better learning achievement. However, in research Al-Azani (2019) the error rate when answering questions has decreased after using the learning media application used in the study. Internet technology used in learning provides insight to students. Through the internet, students can study anytime and anywhere without having to meet the teacher. Learning by using Moodle Increase student participation in learning such as assignment delivery activities, discussions that attract students in learning. So that 
learning using Moodle can improve student learning outcomes in learning (Handayanto, 2018). So it can be said that learning that is assisted by the Android application can increase enthusiasm for learning so that student learning outcomes will increase with the following analysis:

\section{Early Mathematical Ability}

Giving the Initial Mathematical Ability test (EMA) wants to group students according to categories (high, medium, and low) and the differences in EMA in the two groups, namely the PBM and DL groups. The number of EMA in the medium category of the two groups is more than that of the low and high category EMA. The results of the different test on the EMA data in this study indicate that there is no difference in the EMA of students who take lectures in the two groups, either in total (as a whole) or based on each high, medium, and low category. Conditions like this will qualify to apply different treatments to each group in this study. The difference in achievement and increase in PPA was due to differences in treatment between the two groups not due to differences in initial abilities.

\section{Problem Based Learning}

Students still make mistakes. This is possible because the learning and tasks that are applied in this lesson are relatively new to them. The mistakes made in task number 1 include the sentences written in asking the problem which does not question sentences but statements which tend to be adverbial sentences which at the end of the sentence are marked with a period. Task number 2, the student group has compiled the sentence question and it is already a mathematical question/problem, it's just that the sentence structure is not well structured, namely the sentence "determine the odds if:". The sentence is an introduction to two questions with different circumstances. For question (2.a) there is a sentence that can confuse the reader, namely "one paper is taken in a row twice".

\section{Achievement and Improvement of Student PPA}

The highest mean results were obtained from the group of students in the high EMA category and the lowest average was in the group of students in the low EMA category. The mean value of PPA in the high and medium EMA category in the DL class is higher than in PBM class. The difference in the mean score of the PBM and DL classes is not large. Especially for the average PPA, the DL group was bigger than the PBM group. The difference in mean scores between the DL and PBM groups was 8.57. However, it has been tested statistically, and it is concluded that there is no difference in the posttest mean between PBM and DL classes. It appears that the highest mean is obtained from the group of students in the high EMA category and the lowest mean is in the group of students in the low EMA category in the PBM class on all three abilities. The highest and lowest mean $\mathrm{N}$-gain in the class. The difference in the mean scores of the PBM and DL classes is quite large. The difference in mean final test scores for the PBM and DL groups for PPA was 0.11.

The overall average PPA achievement for the DL class was higher than the PBM class, namely 82.71 and 91.28. Although there is no statistically significant difference. This was due to the differences in posttest DL class and PBM class in the medium and low EMA categories, which respectively reached 11.92 and 18.50; Meanwhile, the high EMA category had a not too large difference in achievement, namely 2.38. It can be seen that there is no interaction between the learning approach and EMA on the achievements of PPA. This means that there is no joint influence that the learning approach and students' initial mathematical abilities contribute to the achievement of PPA or it can be said that EMA has no share in the achievement of PPA.

The average increase in PPA overall for the DL class was higher than that for the PBM class although they were both classified as low increases, and there was no statistically significant difference. PBM class has $\mathrm{N}$-gain which is superior to DL class in high and medium EMA category, and vice versa in low EMA category. In the medium EMA category, the average achievement of the DL class is higher than that of the PBM class, but the average increase in the PBM class is higher than the DL class. This happens because the majority value of the PPA pretest value in the KBM class is lower than the PPA pretest value for DL class and the PPA posttest value of the two classes is not much different. This is equivalent to an increase in overall resilience where the PBM class is higher than the DL class.

\section{Student Opinions on Problem Submission Tasks}

Based on the results of the questionnaire given by the students, the majority tended to agree that posing a mathematical problem was a challenging task rather than solving problem, but students tended to strongly agree when the preparation of mathematical problem only changed the numbers in the facts in the main problem. This indicates that students have begun to be challenged and want to solve mathematical problem 
submissions but prefer submission tasks that are not too difficult.

The snippet of the interview with Meks-3 shows that the first freshmen get the task of proposing a mathematical problem and having difficulties at the beginning in preparing the mathematical problem. After trying to overcome difficulties with learning and looking for sources both from books and the internet, students have begun to realize and be optimistic about the goodness of posing a mathematical problem and are optimistic about the benefits that will be obtained during field practice or later when they become teachers.

On the other hand, the majority of students feel happy when they succeed in posing a mathematical problem but still prefer to solve mathematical critical thinking problem rather than pose a mathematical problem. This happens because the proposed mathematical problem must also be able to imagine the solution to the proposed mathematical problem.

\section{Student Difficulties in Asking Mathematical problem}

The results of the statistical test in the previous discussion explained that there was no difference in the average PPA achievement of students who received PBM and DL. This also happened for the category of high, medium, low and total EMA (overall). Based on the distribution of samples that the number of students in the PBM class is 28 with 8 students in the high, 14 medium, and 6 in the low category. The number of students in the PBM class is 28 people with 7 students in the high, 16 medium, and 6 in the low category. The number of questions submitted for the PPA test is divided into unit 1 and unit 2 with 5 it EMA each. The difficulty of students in proposing mathematical problem in the PBM class when viewed from the indicators of proposing a mathematical problem is mostly in "compiling subproblem from the core problem". The achievement on this indicator is only $23 \%$. It was shown that PPA was not an easy thing, because there was only one indicator that could be achieved by more than $60 \%$ by the PBM class. Some indicators that have become difficult for students include: compile sub-questions from a key question, formulate existing questions with the same meaning, and arrange the next question from existing questions by adding new information.

The indicator of arranging sub-questions from a key question becomes student difficulty because students often contain mathematical questions outside the main problem thread or in other words, many students just load the sentence from the questions that are in the data/facts that are in the main problem. Students have difficulty solving a problem with indicators of formulating existing questions with the same meaning because students have to make sentences that are different from the existing sentences in the questions, but the work or new interrogative sentences must have the same meaning as the initial question with the same steps of processing. . Then, students also had a lot of difficulty in "arranging the next question from existing questions by adding new information" because most students only create a new problem without adding new facts/situations to the problem being compiled. Arranging a problem after solving a mathematical problem is also difficult for students because most students create a new problem that is not related to "the previous problem". The difficulty of students in proposing mathematical problem is because the material of Opportunity Theory is more difficult than the material of opportunities in high schools, and it is a new thing for students in posing a mathematical problem. The students' difficulties in posing mathematical problem are following the results of research by Cai (2003)

\section{CONCLUSION}

The ability of a prospective teacher posing problem is still low because they are still unable to develop creative ideas. Prospective teachers still have difficulty raising the issues raised. It is necessary to have innovation in learning so that it has a better problem-posing ability. During a pandemic like this time teaching and learning activities experience many obstacles. To overcome these obstacles, it is necessary to do learning innovations, one of which is online learning. Online learning needs support so that learning can go as expected. Android application-based online learning as a tool that helps maximize teaching and learning activities.

\section{REFERENCES}

Afhara, M. (2013). The influence of learning strategies based on multiple intelligences and learning styles on the learning outcomes of Islamic religious education students at Sabilina Elementary School, Percut Sei Tuan District. (Doctoral dissertation,PascasarjanaUINSumateraUtara). (in Indonesian) http://repository.uinsu.ac.id/1799/1/Tesis\%20Afhara.pdf

Akben, N. (2020). Effects of the problem-posing approach on students' problem-solving skills and 
metacognitive awareness in science education. Research in Science Education, Vol. 50, No. 3, pp: 1143-1165. DOI: 10.1007/s11165-018-9726-7.

Al-Azani, K., Elkatatny, S., Ali, A., Ramadan, E., \& Abdulraheem, A. (2019). Cutting concentration prediction in horizontal and deviated wells using artificial intelligence techniques. Journal of Petroleum Exploration and Production Technology, Vol. 9, No. 4, pp: 2769-2779. DOI: 10.1007/s13202-0190672-3.

Amasha, Mohamed A., Marwa F. Areed, Dalia Khairy, Safaa M. Atawy, Salem Alkhalaf, and Rania A. Abougalala. (2020). Development of a Java-Based Mobile Application for Mathematics Learning. Education and Information Technologies, 1-20. DOI: 10.1007/s10639-020-10287-0.

Barisone, EMAhela, Annamaria Bagnasco, Giuseppe Aleo, Gianluca Catania, Massimo Bona, Stefano Gabriele Scaglia, Milko Zanini, Fiona Timmins, and Loredana Sasso. (2019). The Effectiveness of Web-Based Learning in Supporting the Development of Nursing Students' Practical Skills during Clinical Placements: A Qualitative Study. Nurse Education in Practice, Vol.37, pp:56-61. DOI:10.1016/j.nepr.2019.02.009.

Cai, C. L., Liang, X., Shi, Y., Chu, P. H., Pfaff, S. L., Chen, J., \& Evans, S. (2003). Isl1 identifies a cardiac progenitor population that proliferates the prior to differentiation and contributes a majority of cells to the heart. Developmental cell, Vol. 5, No.6, pp: 877-889. DOI: 10.1016/S1534-5807(03)00363-0.

Cai, J., Chen, T., Li, X., Xu, R., Zhang, S., Hu, Y. \& Song, N. (2019). Exploring the impact of a problem-posing workshop on elementary school mathematics teachers 'conceptions on problem posing and lesson design. International Journal of Educational Research, Vol. 102, 101404. DOI: 10.1016/j.ijer.2019.02.004.

Çakır, A., \& Akkoç, H. (2020). Examining socio-mathematical norms related to problem posing: a case of a gifted and talented mathematics classroom. Educational Studies in Mathematics, Vol. 105, No.1, PP: 19-34. DOI: $10.1007 / \mathrm{s} 10649-020-09965-0$.

Calabrese, J., Kopparla, M., \& Capraro, MM. (2020). Examining young children's multiplication understanding through problem posing. Educational Studies, pp: 1-16. DOI: 10.1080/03055698.2020.1740976.

Chen, T., \& Cai, J. (2020). An elementary mathematics teacher learning to teach using problem posing: A case of the distributive property of multiplication over addition. International Journal of Educational Research, Vol.102, 101420. DOI: 10.1016/j.ijer.2019.03.004.

Cildir, Sema, and Nazan Sezen. (2011). A Study on the Evaluation of Problem Posing Skills in Terms of Academic Success. Procedia Social and Behavioral Sciences, Vol. 15, pp: 2494-2499. DOI: 10.1016/j.sbspro.2011.04.134.

Crespo, S., \& Sinclair, N. (2008). What makes a problem mathematically interesting? Inviting prospective teachers to pose better problems. Journal of Mathematics Teacher Education, Vol. 11, No. 5, pp: 395-415. DOI: 10.1007/s10857-008-9081-0.

Damayanti, Mukhripah, and Dwi Rahmah Fitriani. (2017). The Relation of Educational Level, academic Achievement (GPA) and Depression among Public School Adolescent. IJNP (Indonesian Journal of Nursing Practices), Vol. 1, No. 3, pp: 83-90. DOI: 10.18196/ijnp.1365.

Dharma, Hendy Reginald Weather, Dhaniar Asmarani, and Udiana Puspa Dewi. (2017). Basic Japanese Grammar and Conversation E-Learning through Skype and Zoom Online Application. Procedia Computer Science, Vol. 116, pp: 267-273. DOI: 10.1016/j.procs.2017.10.055

Grice, D. (2019). Church, Society and University: The Paris Condemnation of 1241/4. Routledge. https://books.google.co.id/books?id=s5WnDwAAQBAJ\&lpg=PT7\&ots=X-

aCMQw0pP\&dq=Grice\%2C\%20D.\%202019.\%C2\%A0Church\%2C\%20Society\%20and\%20Univer sity\%3A\%20The\%20Paris\%20Condemnation\%20of\%201241\%2F4.\%20Routledge.\&lr\&pg=PT8 \#v=onepage\&q=Grice,\%20D.\%202019.\%C2\%A0Church,\%20Society\%20and\%20University:\%20 The\%20Paris\%20Condemnation\%20of\%201241/4.\%20Routledge.\&f=false

Guo, M., Leung, FK, \& Hu, X. (2020). Affective determinants of mathematical problem posing: the case of Chinese Miao students. Educational Studies in Mathematics, pp: 1-21. DOI: 10.1007/s10649-02009972-1.

Gupta, PK, and Rashmi Mili. (2016). Impact of academic Motivation on Academic Achievement: A Study on High Schools Students. European Journal of Education Studies. Volume 2, issues 10. DOI: 10.1080/03055698.2020.1740976.

Handayanto, A., Supandi, S., \& Ariyanto, L. (2018, May). Teaching using moodle in mathematics education. In Journal of Physics: Conference Series (Vol. 1013, No. 1, p. 012128). IOP Publishing.

Hardanti, Kurniasari Novi. (2016). Factors That Affect Academic Achievement Student. AKRUAL: Journal of Accounting, Vol.7, No. 2, pp: 93-103. http://journal.unesa.ac.id/php.index/aj.

Husni, Emir. (2013). BIUTIS Mobile Applications: Let's Study Vocabulary Learning as a Media for Children 
with Autism. Procedia Technology, Vol.11, pp: 1147-1155. DOI: 10.1016/j.protcy.2013.12.307.

Hwang, GJ, Huang, H., Wang, RX, \& Zhu, LL. (2020). Effects of a concept mapping- based problem-posing approach on students' learning achievements and critical thinking tendency: An application in Classical Chinese learning contexts. British Journal of Educational Technology.Vol. 0, No. 0, pp. 1-20. DOI: $10.1111 /$ bjet.13007

İPEK, C., \& ACUNER, H. Y. (2011). Sınıf öğretmeni adaylarının bilgisayar öz-yeterlilik inançları ve eğitim teknolojilerine yönelik tutumları. Ahi Evran Üniversitesi Kırşehir Eğitim Fakültesi Dergisi, Vol. 12, No. (2suppl), pp: 23-40. https://app.trdizin.gov.tr/publication/paper/detail/TVRJek1EWTFOUT09

Işık, Cemalettin, Tuğrul Kar, Tuğba Yalçın, and Kıymet Zehir. (2011). Prospective Teachers' Skills in Problem Posing concerning Different Problem Posing Models. Procedia-Social and Behavioral Sciences, Vol. 15: pp. 485-489.DOI: 0.1016/j.sbspro.2011.03.127.

Kar, Tuğrul, Ercan Özdemir, Ali Sabri İpek, and Mustafa Albayrak. (2010). The Relation between the Problem Posing and Problem-Solving Skills of Prospective Elementary Mathematics Teachers. Procedia-Social and Behavioral Sciences, Vol. 2, No. 2, pp.1577-1583. DOI:10.1016/j.sbspro.2010.03.239.

Koichu, B. (2020). Problem posing in the context of teaching for advanced problem-solving. International Journal of Educational Research, vol. 102, 101428. DOI: 10.1016/j.ijer.2019.05.001.

Kularbphettong, K., Putglan, R., Tachpetpaiboon, N., Tongsiri, C., \& Roonrakwit, P. (2015). Developing of mLearning for discrete mathematics based on android platform. Procedia-Social and Behavioral Sciences, Vol. 197, pp: 793-796. DOI: 10.1016/j.sbspro.2015.07.184.

Lange, Christopher, and Jamie Costley. (2020). Improving Online Video Lectures: Learning Challenges Created by Media. International Journal of Educational Technology in Higher Education, Vol. 17, No. 16, pp: 1-18. DOI: 10.1186/s41239-020-00190-6.

Leavy, A., \& Hourigan, M. (2019). Posing mathematically worthwhile problem: developing the problemposing skills of prospective teachers. Journal of Mathematics Teacher Education, Vol. 23, No. 4, pp. 341-361. DOI: 10.1007/s10857-018-09425-w.

Lee, SY. (2020). Research Status of Mathematical Problem Posing in Mathematics Education Journals. International Journal of Science and Mathematics Education, pp.1-17. DOI:10.1007/s10763-02010128-z.

Leikin, R., \& Elgrably, H. (2019). Problem posing through investigations for the development and evaluation of proof-related skills and creativity skills of prospective high school mathematics teachers. International Journal of Educational Research, Vol. 102, 101424. pp. 0883-0355. DOI: 10.1016/j.jer.2019.04.002.

Mohamed, N., Al-Jaroodi, J., Jawhar, I., Idries, A., \& Mohammed, F. (2020). Unmanned aerial vehicles applications in future smart cities. Technological Forecasting and Social Change, Vol. 153, 119293. DOI: 10.1016/j.techfore.2018.05.004.

Rosito, Asina Christina. (2020). Academic Achievement among University Students: The Role of Causal Attribution of academic Success and Failure, and Vol. 7, No. 1, pp:23-33. DOI:10.26555/humanitas.v17i1.11719.

Sari, Azani Cempaka, Andre Mohammad Fadillah, Junaidy Jonathan, and Mahendra Rezky David Prabowo. (2019). Interactive Gamification Learning Media Application For Blind Children Using Android Smartphones in Indonesia. Procedia Computer Science, Vol. 157, pp: 589-595. DOI: 10.1016/j.procs.2019.09.018.

Şengül, S., \& Katranci, Y. (2012). Problem-solving and problem-posing skills of prospective mathematics teachers about the 'sets' subject. Procedia-Social and Behavioral Sciences, Vol. 69, pp: 1650-1655. DOI: $10.1016 / \mathrm{j}$. sbspro.2012.12.111.

Supandi, S. Ariyanto, L., Kusumaningsih, W., \& Aini, A. N. (2018, March). Mobile phone application for mathematics learning. In Journal of Physics: Conference Series (Vol. 983, No. 1, p. 012106). IOP Publishing.

Sung, Eunmo, and Richard E. Mayer. (2013). Online Multimedia Learning with Mobile Devices and Desktop Computers: An Experimental Test of Clark's Methods-Not-Media Hypothesis. Computers in Human Behavior, Vol. 29, No. 3, pp: 639-647. DOI: 10.1016/j.chb.2012.10.022.

Ulya, Rahmatul, Arni Amir, and Yaslinda Yaunin. (2018). Association Between Psychological Profile And academic Achievement of Midwifery Students. Journal of Midwifery, Vol. 3, No. 2, pp: 1-10. http://jom.fk.unand.ac.id.

Vie, Stephanie. (2018). Effective Social Media Use in Online Writing Classes through Universal Design for Learning (UDL) Principles. Computers and Composition Vol. 49, pp: 61-70. DOI: 10.1016/j.compcom.2018.05.005. 
Voice, C., Singer, FM, \& Stan, E. (2020). How are motivation and self-efficacy interacting in problem-solving and problem-posing?. Educational Studies in Mathematics, Vol.105, pp. 487-517. DOI:10.1007/s10649-020-10005-0.

$\mathrm{Xu}$, Binyan, Jinfa Cai, Qimeng Liu, and Stephen Hwang. (2020).Teachers 'Predictions of Students' Mathematical Thinking Related to Problem Posing. International Journal of Educational Research, Vol. 102,101427. DOI: 10.1016/j.ijer.2019.04.005.

Zhang, L., Zhou, Y., \& Wijaya, TT. (2020). Hawgent Dyna EMA mathematics software to improve problemsolving ability in teaching triangles. In Journal of Physics: Conference Series, Vol. 1663, No.1, p. 012069, IOP Publishing. DOI: 10.1088/1742-6596/1663/1/012069 